\title{
A IMPORTÂNCIA DO PLANEJAMENTO DA ROTINA NA EDUCAÇÃO INFANTIL
}

\author{
Cremilda Damascena de Lima Nascimento ${ }^{1}$ \\ Iraci Emídio Silva ${ }^{2}$ \\ Irani Rodrigues Delgado ${ }^{3}$ \\ Rosania Maria dos Santos Silva ${ }^{4}$ \\ Fabiana Maria da Silva ${ }^{5}$
}

\section{RESUMO}

A educação infantil, primeira etapa da educação básica, é uma temática muito discutida na academia. Um cenário muito diferente do passado, em que essa etapa da educação não era valorizada. Partindo da importância de estudar cada vez mais esse tema, o presente trabalho tem como objetivo geral analisar a importância de planejar e estabelecer uma rotina na Educação Infantil. O estudo, de natureza qualitativa, foi realizado a partir de estudo bibliográfico. Os resultados evidenciam que o planejamento da rotina é um aspecto central do trabalho pedagógico na educação infantil, pois orienta a criança na dinâmica da sala de aula; orienta o professor; e organiza o tempo das atividades no espaço educativo. Todos esses aspectos corroboram para ampliar as possibilidades de desenvolvimento da criança e de seus campos de experiências.

Palavras-chave: Rotina. Educação Infantil. Planejamento.

Data de submissão: $22 / 05 / 2020$

Data de aprovação: $27 / 07 / 2020$

\section{INTRODUÇÃO}

O planejamento da rotina de trabalho é visto pelos professores como um documento norteador das atividades diárias, o que nos leva a pensar qual é a importância e os benefícios de se planejar na educação infantil. No entanto, o ato de planejar foi por muitos anos negligenciado pela pouca ou nenhuma importância dada às crianças menores. A partir de

1 Graduanda do curso de pedagogia da FMGR. E-mail: ninha2018.1@outlook.com

2 Graduanda do curso de pedagogia da FMGR. E-mail: iraci_emidio@hotmail.com

3 Graduanda do curso de pedagogia da FMGR. E-mail: iranird23@gmail.com

4 Graduanda do curso de pedagogia da FMGR. E-mail: rosaniamariadss@gmail.com

5 Professora orientadora do curso de Pedagogia da FMGR. E-mail: fabiana.silva1@gmail.com 
1996, a Lei de Diretrizes e Bases (LDB), ao se referir à educação infantil, de forma específica, provoca uma quebra de paradigma em relação à desvalorização da educação infantil, bem como às mudanças nas políticas públicas referentes à infância.

Com a mudança de paradigma, atualmente, a educação infantil e os processos que lhe são subjacentes constituem pauta de pesquisas e estudos no mundo inteiro, sob o olhar de diversos profissionais e pesquisadores de diversas áreas.

Dentro dos vários aspectos da educação infantil, nos chamou atenção a questão do planejamento, da rotina dos docentes, ou seja, a dinâmica que se estabelece nas salas de aula da educação infantil. Assim como nas outras etapas da educação básica, as instituições de ensino que atuam na educação infantil necessitam estabelecer uma rotina para o trabalho do professor que, por meio dela, se desenvolvem os processos de aprendizagem.

Já se sabe que o planejamento da rotina escolar na educação infantil, assim como nas outras etapas, é organizado por horários, tarefas pré-estabelecidas e atividades cotidianas. Sabemos ainda que a dinâmica da educação infantil é diferente, pois precisa corresponder às intencionalidades dessa etapa que, segundo a LDB, é de formar integralmente crianças de até 5 anos, em seus aspectos físico, psicológico, intelectual e social.

Neste contexto, isso significa que a rotina vai fazer com que a criança tenha possibilidade de se orientar na relação tempo e espaço bem como na sua percepção em relação ao mundo e ao outro.

A educação infantil é a primeira etapa de um longo processo. Nesse contexto, é fundamental que seja introduzida uma rotina das atividades para que a criança se sinta segura no desenvolvimento da sua autonomia. É importante reforçar que o planejamento deve ser flexível para respeitar o tempo da criança em seus aspectos físicos e psicológicos. A rotina pode ser vista algumas vezes como ruim e repetitiva, porém as atividades devem ser desenvolvidas de forma que contemplem a participação ativa da criança na realização e construção das noções de tempo e de espaço, além de compreender o modo como as situações são organizadas, permitindo interações sociais.

Assim, essa temática aponta para questionamentos sobre a importância do planejamento e realização da rotina da educação infantil, com que frequência são realizadas, e sobre a existência de um possível parâmetro para realização da mesma. Após estes questionamentos, optou-se por estabelecer um estudo sobre a importância do planejamento da rotina na educação infantil. O intuito da pesquisa é entender como o docente realiza o planejamento das atividades propostas em espaços de educação infantil. É importante ressaltar que, para fins 
dessa pesquisa, delimitamos professores e espaços da educação infantil voltada para crianças das pré-escolas.

A referida temática tornou-se o motivo dessa pesquisa por ser uma atividade realizada de forma constante pelos profissionais da educação, e por entender que o planejamento é fundamentalmente importante para estruturar, transformar e realizar atividades do cotidiano do professor.

A escolha do tema surgiu a partir da própria experiência com o estágio supervisionado. Após perceber a inquietação das docentes ao planejar as atividades, foi possível observar a dificuldade de cumprir as etapas propostas no planejamento no tempo determinado para cada atividade, bem como a observação das dificuldades apresentadas no dia a dia em sala de aula da educação infantil onde trabalham.

O tema se faz relevante por sua importância no contexto social e educacional. O planejar da rotina é a base do cotidiano escolar. Sua importância é diária e agrega uma melhoria no contexto social da criança em relação à convivência com o grupo em que estão inseridas.

Dentre essas melhorias temos a aceitação da rotina, melhoria nas atividades diárias, no convívio tanto com sua turma quanto com os demais no âmbito escolar. A presente pesquisa pretende apresentar subsídios que auxiliem e que também traga novos elementos para o debate acerca dessa temática.

\section{FUNDAMENTAÇÃO TEÓRICA}

\section{Instrumentos Reguladores da Educação Infantil}

Os documentos normativos que regulam a educação infantil possuem datas relativamente recentes, tendo em vista a falta de reconhecimento da educação infantil como função do Estado, que só aconteceu em 1988 a partir da Constituição Federal, depois de muitas reivindicações de movimentos sociais, movimento de mulheres e de profissionais da educação.

A Lei de Diretrizes e Bases da Educação (LDB n ${ }^{0}$ 9394/96) foi um marco histórico e legislativo bem importante para a educação infantil, pois trouxe melhorias para o atendimento educacional de crianças pequenas. Ela integrou as creches aos sistemas de ensino, formando, junto com as pré-escolas, a primeira etapa da Educação Básica. De 1996 até os dias atuais, a 
educação infantil passou por reformulações. Da seção II, que trata da educação infantil na LDB, destacamos os artigos a seguir:

\footnotetext{
Art. 29. A educação infantil, primeira etapa da educação básica, tem como finalidade o desenvolvimento integral da criança de até 5 (cinco) anos, em seus aspectos físico, psicológico, intelectual e social, complementando a ação da família e da comunidade.

Art. 30. A educação infantil será oferecida em:

I - Creches, ou entidades equivalentes, para crianças de até três anos de idade;

II - Pré-escolas, para as crianças de 4 (quatro) a 5 (cinco) anos de idade. (BRASIL, 1996).
}

O artigo 29 explicita as finalidades da educação infantil e destaca a necessidade desta modalidade em promover o desenvolvimento integral da criança, o que nos indica uma maior consideração em reação à visão da criança pequena enquanto sujeito. Já no artigo 30 a LDB demarca, em redação recente, as idades e suas etapas correspondentes.

Segundo a Lei de Diretrizes de Base (LDB), aos profissionais da educação cabem participar da elaboração da proposta pedagógica do estabelecimento de ensino. A lei determina ainda que cada docente deve elaborar e cumprir um plano de trabalho, segundo a proposta pedagógica. Ela também reforça que o plano é uma das atividades mais acadêmicas, produtivas e interessante dos profissionais de ensino, pois a partir dele o docente projeta suas metas curriculares e educacionais.

Outro documento fundamental para a compreensão da educação infantil são as Diretrizes Curriculares Nacional para a Educação Infantil (DCNEI), fixadas pela Resolução n ${ }^{\circ}$ 5, de 17 de dezembro de 2009. Esse documento é muito importante, pois apresenta diretrizes para a organização das propostas pedagógicas na educação infantil, incluindo currículo, avaliação e demais procedimentos indispensáveis para esta etapa da Educação Básica. Deste documento destacamos novamente a percepção a respeito das crianças pequenas. No artigo $4^{\circ}$ temos:

\footnotetext{
Art. $4^{\circ}$ As propostas pedagógicas da Educação Infantil deverão considerar que a criança, centro do planejamento curricular, é sujeito histórico e de direitos que, nas interações, relações e práticas cotidianas que vivencia, constrói sua identidade pessoal e coletiva, brinca, imagina, fantasia, deseja, aprende, observa, experimenta, narra, questiona e constrói sentidos sobre a natureza e a sociedade, produzindo cultura. (BRASIL, 2009).
}

Como é possível observar, as crianças são colocadas como sujeito histórico e de direito, um aspecto bem diferente em relação à visão antiga que pairou sobre os determinantes educacionais ao longo da história do ensino no Brasil. 
Nesse processo, a organização do trabalho pedagógico deve abranger diferentes dimensões, valorizando as interações, as brincadeiras e os jogos, além do cuidar e educar nas práticas cotidianas. No currículo deve estar presente o conjunto de práticas que busca articular as experiências e os saberes da criança. Além disso, a proposta deve respeitar os princípios éticos, políticos e estéticos que garantem e ampliam a aprendizagem e o desenvolvimento infantil por meios de diferentes recursos.

Também merece destaque o Plano Nacional da Educação (PNE) e sua atenção à educação infantil. Este documento representa um conjunto de metas e estratégias para melhorar a educação nacional no prazo de 20 anos, a partir de sua aprovação, que se deu pela Lei $n^{\circ}$ 13.005 em 2014. O PNE reservou uma meta exclusiva para a educação infantil:

META 1 Universalizar, até 2016, a educação infantil na pré-escola para as crianças de 4 (quatro) a 5 (cinco) anos de idade e ampliar a oferta de educação infantil em creches de forma a atender, no mínimo, 50\% (cinquenta por cento) das crianças de até 3 (três) anos até o final da vigência deste PNE. (BRASIL, 2014).

De acordo com a Lei que estabelece este documento, os dados de acompanhamento e cumprimento da meta mostram, através do indicador, que o percentual da população (de 4 a 5 anos) que frequenta a escola/creche/CMEIs já alcançou essa meta $(81,4 \%)$.

Outro documento importante que orienta a educação infantil são os Parâmetros Nacionais de Qualidade para a Educação Infantil, por ser este um documento padrão que regulariza e orienta as instituições. Esse documento foi inicialmente publicado em 2006, mas a partir da necessidade de uma correspondência com o contexto atual, outra versão foi organizada em 2018 e publicada com o objetivo de se constituir como referência para a organização e o funcionamento das instituições de educação infantil.

Ainda de acordo com o Ministério da Educação e Secretaria de Educação Básica, este documento também descreve a criança como um sujeito social e histórico que está inserido em uma sociedade na qual partilha de uma determinada cultura. A criança é profundamente marcada pelo meio social em que se desenvolve, mas também contribui com ele. (BRASIL, 1994).

Neste contexto, as atividades realizadas nas escolas têm que auxiliar no desenvolvimento das crianças, proporcionando a elas conhecimentos sociais que as possibilitem entender sua realidade e o meio em que estão inseridos, bem como auxiliar a se desenvolverem individualmente, contribuindo com a sociedade em que vivem.

Ainda com relação aos referenciais legislativos, podemos também citar a Base Nacional Curricular Comum (BNCC, 2017), que foi organizada a partir das Diretrizes Curriculares para 
a Educação Infantil, citada anteriormente. A partir deste documento, a educação infantil passa a ser obrigatoriamente regularizada como uma das etapas da Educação Básica. Esse documento propõe que parte do trabalho do educador é refletir, selecionar, organizar, planejar, mediar e monitorar o conjunto das práticas e interações, garantindo a pluralidade de situações que promovam o desenvolvimento pleno das crianças. Dentre outras referências para a educação infantil

A proposta de currículo da BNCC da Educação Infantil organiza-se pelos direitos de aprendizagem e desenvolvimento, campos de experiências e objetivos de aprendizagem e desenvolvimento, elementos que se integram na articulação entre as necessidades, interesses, experiências e curiosidades das crianças de 0 a 5 anos e o patrimônio artístico, cultural, ambiental, científico e tecnológico. (SEB/2018, p. 20).

Como visto anteriormente, as DCNS definem a criança como sujeito histórico e de direito. Neste contexto, a Base Nacional Comum Curricular (BNCC) compreende a criança como um ser integral e complexo. Dessa forma, visa garantir seu desenvolvimento com a proposta dos eixos estruturadores das práticas pedagógicas e as competências gerais na educação básica, onde estão contidos os seis direitos de aprendizagem que são eles: conviver, brincar, participar, explorar, expressar e conhecer-se. Ainda para assegurar o desenvolvimento na educação infantil, este documento traz os campos de experiências que constituem um arranjo curricular que acolhe as experiências concretas da vida cotidiana das crianças e seus saberes.

Estes campos são divididos em cinco: 1) o eu, o outro e o nós; 2) corpo, gestos e movimentos; 3) traços, sons, cores e formas; 4) escuta, fala, pensamento e imaginação; 5) espaços, tempo, quantidades, relações e transformações. A partir dessas estruturas entende-se que as crianças aprendam e se desenvolvam nas situações que possam desempenhar um papel ativo.

\section{Importância do Planejamento na Educação Infantil}

Para compreender o trabalho pedagógico na educação infantil se faz necessário compreender a importância do planejamento, porém, antes disso, é necessário admitir a complexidade que envolve o trabalho pedagógico em qualquer processo educativo. Para Zabala (1998): 
quando não impossível, a tentativa de encontrar referências ou modelos para racionalizar a prática educativa. (ZABALA, 2018, p. 14).

Entendendo que o trabalho pedagógico é complexo por sua grande quantidade de variáveis, é necessário um pensar permanente e sistemático sobre a prática, não no sentido de engessar o processo, mas no sentido de buscar melhores resultados.

Para Luckesi (2011), o ser humano age em função de construir resultados. O ato de planejar é a atividade intencional pela qual se projetam fins e se estabelecem meios para atingi-los. Por isso, não é neutro, mas ideologicamente comprometido. $\mathrm{O}$ ato de planejar, como todos os outros atos humanos, implica escolha que subsidia o ser humano no encaminhamento de suas ações e obtenção de resultados desejados (LUCKESI, 2011).

Neste contexto, podemos analisar o ato de planejar como sendo a teoria e as ações executadas a partir dele como a prática ou a sistematização do que foi planejado. Nesse movimento, os docentes podem enriquecer seu fazer pedagógico com suas metodologias. Nas escolas em geral, o ato de planejar acontece como um modo de instrumentalizar o professor para o uso dos recursos. Dessa forma, o professor pode trabalhar com preenchimento de formulários, tabelas, colunas, entre outros, nos quais os docentes devem registrar as atividades durante o ano letivo na disciplina ou na área de estudos que trabalham e o conjunto dessas ações coordenadas entre si colaboram para a obtenção do resultado desejado.

Estes comandos tornam-se processos que consistem em arquitetar o planejamento através de decisões concisas, visando à obtenção dos resultados. É nessa perspectiva que o planejamento é um elemento fundamental para estruturar o trabalho pedagógico na educação infantil, pois é através desta ferramenta que o docente reflete e busca elementos para traçar as metas que deseja alcançar em suas práticas.

\section{Organização da Rotina}

A rotina compreende o desenvolvimento prático que se consolida no dia a dia com as diferentes atividades, proporciona ações nas quais as crianças adquirem experiências no conhecer, no explorar, no buscar, no questionar, imitar, entre outros aspectos relativos à educação infantil. Já o planejamento é a proposta das atividades que devem ser desenvolvidas. Nas instituições educacionais que ofertam educação infantil, a rotina de sala de aula pode ser estruturada através do planejamento organizado pela coordenação, por um grupo de professores e, em outros casos, por cada professor (a) de forma individual. Habitualmente, a coordenação pedagógica explica a rotina do segmento em relação a vários momentos do dia 
como a acolhida, entrada, atividades didáticas, chamada, lanche, parque e largada. Em seguida os professores que trabalham individualmente constroem seus planejamentos com a rotina de atividades, estipulando a dinâmica desses momentos.

Quando é um determinado grupo de professoras, quase sempre constituída pelos que trabalham na mesma turma, preestabelecem em seus planejamentos uma rotina padrão, incluindo a didática das atividades. Planejar os objetivos que devem ser alcançados nessa construção irá beneficiar professor e aluno, pois a rotina é a junção de todas as atividades que serão realizadas, fragmentas pelo tempo e espaço que a escola oferece, sendo também analisadas as necessidades das crianças. Para os docentes, planejar a rotina das atividades a serem desenvolvidas diariamente é fundamental. Essa ação auxilia na tomada de decisão, otimizando o tempo e tornando a aprendizagem mais eficiente e eficaz.

Desta forma, entende-se que é necessário que exista uma rotina diária que se adeque às necessidades básicas da criança na educação infantil, incentivando-a a descobrir o mundo a sua volta. Essa conscientização vai sendo reforçada em seu cotidiano com apresentação de atividades que irão repercutir na rotina diária de como devem ser realizadas e quais os benefícios. Entende-se ainda que planejar as etapas de uma rotina deve ser formulada com base nos Parâmetros da Educação Infantil, Base Nacional Comum Curricular (BNCC), Diretrizes Curriculares Nacionais para Educação Infantil (DCNEI), por entender que tais documentos atendem às especificidades nesta etapa da educação.

Nesse caso, pressupõe-se que os profissionais que nela atuam estabeleçam práticas que potencializem o desenvolvimento e a aprendizagem, o social e o emocional. Além de espaços adequados, é importante ter um ambiente de aprendizagem que permita às crianças liberdade para exercitarem sua cognição e potencializar seus laços afetivos.

Sobre esses benefícios, Massena (2011) postula que é fundamental que, dentre os elementos que compõem a rotina, façam parte os horários de alimentação, higiene, escovação dos dentes, calendário, chamada, roda de música, oração, momento da novidade, ajudante do dia, hora do conto, repouso, atividades lúdicas e significativas, jogos diversificados, exploração de diversos materiais que estimulem o desenvolvimento da criança. (MASSENA, 2011).

Assim, teremos que observar todos os aspectos destinados à educação infantil, acompanhando tudo de perto e considerando as peculiaridades, dificuldades e especialidades de cada um, tendo em vista que o modo de pensar, sentir e agir delas são diferentes.

Sendo assim, planejar a rotina é de extrema importância no desenvolvimento das atividades na educação infantil, pois é ela que norteia e proporciona a construção do 
conhecimento da criança e, consequentemente, no aprimoramento da sua aprendizagem. Não tornar esse momento como algo mecânico, rígido, é o que dará significado para a criança. Além de ela sentir confiança e segurança, irá se sentir acolhida pelo grupo. Isso irá favorecer e facilitar o processo de internalização da rotina planejada no âmbito escolar.

Léia Tiriba (2010) descreve a rotina como um momento padrão e ao mesmo tempo sutil que, para ser realizado, tem que existir uma pedagogia que respeite as vontades do corpo da criança para que possa se manter viva a potência infantil. Ela observa que o livre movimento dos corpos está na sua origem, assim possibilitando o encantamento, o questionamento, a indagação e o conhecimento das crianças em relação ao mundo físico e social, ao tempo e à natureza (TIRIBA, 2010, p. 5).

Diante dos benefícios acerca do planejamento das rotinas diárias no âmbito da educação infantil, entende-se que este é um instrumento norteador, em que os docentes podem e devem se apoiar para melhorar seu desempenho diário. De acordo com Nunes (1995), a rotina escolar deve favorecer o conhecimento de si nas dimensões física, afetiva e cognitiva, sendo necessário que cada criança possa se perceber como personalidade diferenciada. Dessa forma, entende-se $\mathrm{o}$ ato de planejar a rotina das atividades na educação infantil como uma possibilidade de o docente encontrar soluções para o desenvolvimento e avanço das diversas áreas do conhecimento da criança.

\section{Benefícios do Planejamento e Rotina na Literatura}

Para alcançar nosso objetivo geral e compreender melhor o planejamento como ferramenta do trabalho pedagógico na educação infantil, a presente pesquisa demandou uma análise sobre como a literatura trata o planejamento, além de facilitar nossa compreensão, trazer visões diferentes sobre um mesmo objeto de análise e enriquecer conceitualmente este trabalho.

Resolvemos organizar um quadro informativo que pudesse sintetizar e evidenciar os nossos achados conceituais, conforme apresentamos a seguir: 


\section{Quadro 1 - Informativo de achados conceituais}

\begin{tabular}{|c|c|c|}
\hline ARTIGOS & AUTORES & $\begin{array}{l}\text { ACHADOS CONCEITUAIS SOBRE O PLANEJAMENTO E } \\
\text { ROTINA DA EDUCAÇÃO INFANTIL }\end{array}$ \\
\hline Artigo 1 & $\begin{array}{l}\text { PROENÇA } \\
\text { (2004) }\end{array}$ & $\begin{array}{l}\text { Proença defende a rotina como forma capaz de estruturar atividades } \\
\text { cotidianas, pois a rotina torna-se uma âncora do dia-a- dia, por } \\
\text { representar para a criança e para os professores uma fonte de segurança } \\
\text { e de previsão do que vai acontecer. Nessa visão a rotina norteia, } \\
\text { organiza e orienta o grupo no espaço escolar, além de otimizar o } \\
\text { tempo. }\end{array}$ \\
\hline Artigo 2 & $\begin{array}{l}\text { BARBOSA } \\
\text { (2006) }\end{array}$ & $\begin{array}{l}\text { Para Barbosa, a rotina é uma categoria pedagógica da iducação infantil } \\
\text { que, por meio dela, os educadores se baseiam para estruturar a divisão } \\
\text { do tempo. Ainda de acordo, todas as atividades devem fazer parte da } \\
\text { rotina. }\end{array}$ \\
\hline Artigo 3 & $\begin{array}{l}\text { TIRIBA } \\
(2010)\end{array}$ & $\begin{array}{l}\text { Tiriba descreve a rotina como um momento padrão e ao mesmo tempo } \\
\text { sutil, que para ser realizado tem que existir uma pedagogia que respeite } \\
\text { as vontades do corpo da criança para que possa se manter viva a } \\
\text { potência infantil. }\end{array}$ \\
\hline Artigo 4 & $\begin{array}{l}\text { FREIRE } \\
(2015)\end{array}$ & $\begin{array}{l}\text { Para Freire, a rotina estrutura o tempo, espaço e as atividades onde os } \\
\text { conteúdos são estudados. A criança, para construir o conceito de } \\
\text { tempo, percorre um longo processo. É nesse sentido que a rotina é o } \\
\text { alicerce básico para que os grupos construam seus vínculos. }\end{array}$ \\
\hline Artigo 5 & $\begin{array}{l}\text { COUTINHO } \\
\text { (2002) }\end{array}$ & $\begin{array}{l}\text { Para Coutinho a boa utilização do tempo será refletida no } \\
\text { desenvolvimento dos alunos, portanto, entende-se que a rotina } \\
\text { planejada deve fazer parte do planejamento de cada instituição. }\end{array}$ \\
\hline Artigo 6 & $\begin{array}{l}\text { DIAS } \\
(2010)\end{array}$ & $\begin{array}{l}\text { De acordo com Dias, as atividades planejadas devem contar com a } \\
\text { participação ativa das crianças, garantindo às mesmas a construção do } \\
\text { tempo e de espaço, possibilitando-lhes a compreensão do modo como } \\
\text { as situações são organizadas e, sobretudo, permitindo ricas e variadas } \\
\text { interações socias. }\end{array}$ \\
\hline Artigo 7 & $\begin{array}{l}\text { LUCKESI } \\
\text { (2011) }\end{array}$ & $\begin{array}{l}\text { Para Luckesi, a atividade de planejar é um modo de dimensionar } \\
\text { tecnicamente a atividade escolar, devendo ser elaborada conjuntamente } \\
\text { (professor, coordenação e direção), para decidir oque e como fazer. }\end{array}$ \\
\hline
\end{tabular}




\begin{tabular}{|c|l|l|}
\hline \multirow{2}{*}{ Artigo 8 } & $\begin{array}{l}\text { LIBÂNEO } \\
(2013)\end{array}$ & $\begin{array}{l}\text { Para Libâneo, a ação de planejar é a previsão das ações docentes } \\
\text { fundamentadas em opções político-pedagógicas, tendo como } \\
\text { referências permanentes as situações didáticas concretas. }\end{array}$ \\
\hline
\end{tabular}

\section{Fonte: as autoras}

Após a análise do material entendemos que planejar a rotina na educação infantil é necessário para que o educador organize e estruture suas atividades cotidianas, além de respeitar as individualidades. Esse planejamento não deve ser repetitivo nem cansativo para que não se torne uma forma de desestimular as crianças nas atividades rotineiras.

\section{METODOLOGIA}

Para atender aos objetivos, optou-se por uma pesquisa exploratória de natureza qualitativa na tentativa de favorecer a compreensão da realidade pesquisada. O procedimento para coleta dos dados se deu através de pesquisa bibliográfica em documentos regulamentadores a partir de plataformas da internet (Scielo, Google Acadêmico), onde foram selecionados e coletados dados e artigos acadêmicos referentes ao tema desta pesquisa. Em seguida foi feito um estudo com os trabalhos selecionados, bem como os teóricos que dão embasamento ao tema da pesquisa.

Seguimos as etapas subjacentes à pesquisa bibliográfica, conforme Gil (2017): (1) escolhemos o tema; (2) fizemos o levantamento bibliográfico pre liminar para sondar a quantidade de pesquisas disponível e de fácil acesso; (3) formulação do problema; (4) elaboração do plano provisório do assunto; (5) busca das fontes; (6) leitura do material; (7) fichamento; (8) organização lógica do assunto; (9) redação do texto.

\section{DISCUSSÕES E RESULTADOS}

A condução da pesquisa, o referencial teórico e os nossos achados conceituais nos revelaram resultados importantes sobre o planejamento como ferramenta do trabalho pedagógico na educação infantil.

Quando estudamos sobre as legislações que tratam da educação infantil, com intuito de compreender o contexto de trabalho e as orientações normativas que delineiam a ação pedagógica, descobrimos que estes são instrumentos reguladores e norteadores nos quais os 
docentes devem se apoiar para melhorar suas práticas, favorecendo o desenvolvimento infantil em todos os campos da aprendizagem.

Percebemos ainda que no contexto histórico, na evolução e nas políticas públicas para educação infantil, o percurso percorrido foi lento por não haver um entendimento de que a criança necessitava de uma atenção especial nos primeiros anos de vida.

Com a criação da BNCC, PNEI e LDB, a educação infantil passa a ter mais atenção e é inserida como a primeira etapa da educação básica, devendo abranger crianças de 0 a 5 anos e ser ofertada em creches, CMEIs e pré-escolas. Apesar dos avanços obtidos nessa etapa de educação, percebe-se que muito ainda precisa ser feito para diminuir a distância entre a legislação e a realidade.

Com relação aos conceitos que tratam sobre planejamento da rotina na educação infantil, a pesquisa revelou e evidenciou a sua importância para o trabalho pedagógico no sentido do alcance das metas no decorrer do dia a dia.

A partir da análise dos conceitos organizados no quadro, identificamos que o planejamento da rotina é importante a partir de aspectos diferentes. Esses aspectos foram organizados em categorias. Assim, o planejamento da rotina é importante para: Orientação da criança; 2- Orientação do professor; 3- Organização do tempo; 4- Organização do espaço.

Para esta análise, construímos um quadro com as categorias citadas a partir dos artigos.

Quadro 2 - categorias identificadas nos artigos

\begin{tabular}{|c|c|c|c|c|c|c|c|c|}
\hline $\begin{array}{c}\text { Categorias } \\
\text { identificadas a } \\
\text { partir da } \\
\text { argumentação } \\
\text { encontrada nos } \\
\text { artigos }\end{array}$ & $\begin{array}{c}\text { Artigo } 1 \\
\text { Proença } \\
(2004)\end{array}$ & $\begin{array}{c}\text { Artigo } 2 \\
\text { Barbosa } \\
(2006)\end{array}$ & $\begin{array}{c}\text { Artigo } 3 \\
\text { Tiriba } \\
(2010)\end{array}$ & $\begin{array}{l}\text { Artigo } 4 \\
\text { Freire } \\
(2015)\end{array}$ & $\begin{array}{c}\text { Artigo } 5 \\
\text { Coutinho } \\
(2002)\end{array}$ & $\begin{array}{c}\text { Artigo } 6 \\
\text { Dias } \\
(2010)\end{array}$ & $\begin{array}{c}\text { Artigo } 7 \\
\text { Luckesi } \\
(2011)\end{array}$ & $\begin{array}{c}\text { Artigo } 8 \\
\text { Libâneo } \\
(2013)\end{array}$ \\
\hline $\begin{array}{l}\text { Orientação da } \\
\text { criança }\end{array}$ & $X$ & & $X$ & $X$ & $X$ & $X$ & & \\
\hline $\begin{array}{l}\text { Orientação do } \\
\text { professor }\end{array}$ & $X$ & $X$ & & X & & & $X$ & $X$ \\
\hline $\begin{array}{l}\text { Organização } \\
\text { do tempo }\end{array}$ & X & $X$ & & $X$ & $X$ & X & & \\
\hline $\begin{array}{l}\text { Organização } \\
\text { do espaço }\end{array}$ & $\mathrm{X}$ & & & $X$ & & $X$ & & \\
\hline
\end{tabular}

Fonte: as autoras

A análise dos artigos e referenciais teóricos evidencia a importância para o educador ao fazer uso do planejamento da rotina para alcance de suas metas no decorrer do dia a dia, bem 
como a importância da rotina na evolução do desenvolvimento das crianças. Identificamos também a rotina como aspecto estrutural na educação infantil, e que tem muita relação com as famílias.

Nesta concepção, os pais sentem cada vez mais a importância do espaço escolar, por entender que nesses espaços segue-se uma rotina planejada e estruturada, valorizando o desenvolvimento da criança em todos os processos, otimizando o tempo da melhor forma para não tornar o momento repetitivo e cansativo para os alunos.

Diante dos fatos e acontecimentos em que a rotina é alterada, a dificuldade é manter a disciplina. O desafio para educadores e pais é tornar essa rotina no âmbito "familiar" prazerosa e atraente, promovendo atividades cotidianas que contribuam para o desenvolvimento integral da criança em seus aspectos físicos, psicológicos, intelectual e social. Educadores e pais estão constantemente se reinventando para fazer com que elas sintam prazer em realizar suas atividades pedagógicas, rotineiras e cotidianas, mesmo estando fora do espaço escolar.

O planejamento da rotina é uma ferramenta que orienta e possibilita estruturar o passo a passo na construção do aprendizado, oferece segurança na previsão futura, diminui a ansiedade e favorece o melhor aproveitamento das atividades. É através dessa estrutura que o docente deve refletir nas suas práticas pedagógicas. Nos planejamentos merecem destaque os momentos das atividades organizadas, nos quais as crianças podem se expressar através de atividades coordenadas, brincadeiras, gestos, choro e da fala, contribuindo assim para uma rotina organizada e prazerosa.

Em relação ao tempo e espaço, podemos destacar a forma como as crianças se comportam nos espaços onde ocorrem as atividades, se existe o choro ou resistência em permanecer em um determinado lugar bem como o tempo determinado para que as atividades rotineiras não sejam cansativas a ponto de desestimular o aprendizado.

Essa análise aponta para a importância do planejamento na educação infantil cujo foco principal é auxiliar o professor. Através dessa estruturação, a rotina mostra-se eficiente para valorizar os campos de desenvolvimento e aprendizagem, ser prazerosa para estimular as crianças, além de otimizar o tempo e a organização nos espaços adequados para as atividades rotineiras. 


\section{CONSIDERAÇÕES FINAIS}

A presente pesquisa teve como objetivo geral analisar a importância de planejar e estabelecer uma rotina na educação infantil e foi realizada a partir de pesquisa bibliográfica.

Os estudos destacaram a importância da educação infantil como etapa primeira da escolaridade dos indivíduos e que nela o trabalho pedagógico está centrado em um bom planejamento, que favoreça o desenvolvimento das crianças a partir dos campos de experiências. A importância de planejar e estabelecer uma rotina na educação infantil está diretamente ligada à qualidade do trabalho pedagógico nesta etapa, pois o planejamento da rotina orienta o professor com relação à dinâmica no espaço escolar, mas, principalmente, orienta a criança que precisa estabelecer uma rotina de atividades com segurança e autonomia.

De fato, concluímos que planejar a rotina é um processo fundamental para auxiliar o professor na construção de sua prática pedagógica, bem como na construção do desenvolvimento, do conhecimento e do pensar das crianças.

Finalizamos este breve estudo com o desejo de que pesquisadores sigam investigando as práticas pedagógicas inerentes à profissão, principalmente no campo da educação infantil, visando ampliar e aprimorar os conhecimentos para que tenhamos outros estudos sobre a temática, a partir de outras perspectivas.

\section{REFERÊNCIAS}

BARBOSA, Maria C. S. A rotina das pedagogias na educação infantil: dos binarismos à complexidade. Currículo sem Fronteiras. v. 6, n. 1, p. 56-69. Disponível em: http://www.curriculosemfronteiras.org/vol6iss1articles/barbosa.pdf. Acesso em: 20 jan. 2020.

BASSEDAS, Eulália; HUGUET, Teresa; SOLE, Isabel. Aprender e Ensinar na Educação Infantil. Porto Alegre: Artes Médicas, 1999.

BILORIA, Jéssica Ferreira; METZNER, Andréia Cristina. A importância da rotina na educação infantil. Revista Fafibe On-Line. ano VI, n.6. nov. 2013. Disponível em: http://www.unifafibe.com.br/revistasonline/arquivos/revistafafibeonline/sumario/28/1112201 3185355.pdf. Acesso em: 30 maio 2020. 
BRASIL. Ministério da Educação. Secretaria da Educação Básica. Base Nacional Comum Curricular. Brasília, $2017 . \quad$ DF, em: http://basenacionalcomum.mec.gov.br/images/BNCC_EI_EF_110518_versaofinal_site. pdf Acesso em: 23 mar. 2020.

BRASIL. Instituto Nacional de Estudos e Pesquisas Educacionais Anísio Teixeira. Plano Nacional de Educação PNE 2014-2024 : Linha de Base. - Brasília, DF : Inep, 2015. Disponível em: https://www.deolhonosplanos.org.br/wpcontent/uploads/2015/10/Plano_Nacional_de_Educacao_Linha_De_Base.pdf. Acesso em :17 jun. 2020.

BRASIL. Lei de Diretrizes e Bases da Educação Nacional, LDB 9.394, de 20 de dezembro de 1996. Disponível em: http://www.planalto.gov.br/ccivil_03/leis/19394.htm. Acesso em: 16 jan. 2020.

BRASIL. Lei federal $\mathbf{n}^{\mathbf{0}} \mathbf{1 2 . 7 9 6}$ Disponível em: http://www.planalto.gov.br/ccivil_03/_Ato2011-2014/2013/Lei/L12796.htm. Acesso em: 18 jun.2020.

CARDONA, M. J. A organização do espaço e do tempo na sala de jardim-de- infância. Cadernos de Educação de Infầncia, (24), 1992.

FREIRE, Madalena. Rotinas construção do tempo na relação pedagógica. Cadernos de Reflexão. São $\quad$ Paulo, $1993 . \quad$ Disponível em: http://www.cchla.ufrn.br/shXVIII/artigos/GT33/com\%20Oral\%20para\%20os\%20 anais\%20do\%20CCHLA.pdf- Acesso em: 30 maio 2020.

LUCKESI, Cipriano Carlos. Avaliação da aprendizagem escolar: estudos e proposições. 22. ed. São Paulo: Cortez, 2011.

MASSENA, Renata S. Entrelaçamentos Entre as Concepções do Educar e do Cuidar na Educação Infantil.

MINAYO, M. C. S. (org.). Pesquisa Social. Teoria, Método e Criatividade. Petrópolis: Vozes, 1995.

NUNES, Nadir Neves. O ingresso na pré-escola: uma leitura psicogenética. In: OLIVEIRA, Zilma de M. R. (org.). A criança e seu desenvolvimento. São Paulo: Cortez, 1995.

OSTETTO, Luciana Esmeralda (Org.). Encontros e encantamentos na educação infantil: partilhando experiências de estágios. Campinas, SP: Papirus, 2000.

SCHEWTSCHIK, Annaly. O planejamento de aula: um instrumento de garantia de aprendizagem. Disponível em:

https://educere.bruc.com.br/arquivo/pdf2017/26724_13673.pdf. Acesso em: 30 maio 2020. 
SOARES, Carla; BENCINI, Roberta. Quatro razões para fazer da rotina sua aliada. Disponível em: https://novaescola.org.br/conteudo/1868/quatro-razoes- para-fazer-da-rotinasua-aliada. Acesso em: 20 abr. 2020.

TIRIBA, Léa. Crianças, natureza e educação infantil. (Tese de Doutorado) Departamento de Educação, PUC-RIO, 2005.

WARSCHAUER, Cecília. A roda e o registro: uma parceria entre professor, alunos e conhecimento. Rio de Janeiro: Paz e Terra, 1993. 